\title{
RODRIGO NIÑO, EL DE LOS GALEOTES
}

El nacimiento del mundo colonial, desde su tormentoso primer siglo, atrajo más de una vez la atención de Alfonso Reyes. Hay ejemplos claros. Cuando, todavía joven, don Alfonso se topó con el cartapacio de Mateo Rosas de Oquendo, palpó en esas sátiras la temprana rivalidad entre indianos y peninsulares, fuese en México, Lima u otros lugares. En 1917 publicó un artículo sobre Oquendo "y sus andanzas" "; esas páginas no pasaron inadvertidas: llegaron empapadas del espíritu de esos inicios; más tarde las recogió en Capítulos de literatura española ${ }^{2}$. Aquella "musa errabunda y aventurera" de "risueño coplero" reaparecerá en párrafos de Letras de la Nueva España; con razón advierte que hay allí textos atribuidos "sin certeza, porque [...] mezclaba lo propio y lo ajeno" en "su zurrón de viaje"'3. Así fue y ahora consta. En esas mismas Letras novohispanas (lectura deleitosa, cuajada de penetrantes observaciones) desfilan viejos cronistas, apegados al suelo americano; también se hallarán los primeros humanistas, poetas, y autores teatrales, como Cervantes de Salazar, González de Eslava, Terrazas y muchos más. El transplante había arraigado.

De esos escritores surgirán frutos varios: muchos con mezcla de verdad y fantasía, en proporciones distintas según autores y circunstancias. Si parecida mixtura aparecía en Europa, con mayor motivo en Indias. Los temas lo pedían. De los hechos insólitos de la Conquista se pasaba a su evocación. El amor al terruño

${ }^{1}$ Alfonso Reyes, "Sobre Mateo Rosas' de Oquendo, poeta del siglo $\mathrm{XVI}$ ", RFE, 4 (1917), 341-370.

${ }^{2}$ Alfonso Reyes, Capitulos de literatura española (primera serie), La Casa de España en México, México, 1939, pp. 217 ss; Pasado inmediato y otros ensayos, El Colegio de México, México, 1941, cap. 3.

${ }^{3}$ Alfonso Reyes, Letras de la Nueva España, FGE, México-Buenos Aires, 1948, caps. 1-5. Basten estos ejemplos. 
se afirmaba igual en México que, por ejemplo, en el Perú: allí también criollos, mestizos y colonos peninsulares tomarán la pluma y hablarán de aquello suyo. Un donoso episodio narrado por el Inca Garcilaso, el de Rodrigo Niño y sus galeotes, puede servir de ejemplo. Serán primicias literarias que hablan de gentes ya apegadas a ese suelo.

El relato ha originado, como tantos de entonces, dudas más insinuadas que sustentadas; habrá, pues, otra razón para escoger el tema.

\section{EL EPISODIO}

Garcilaso Inca solía intercalar en su obra, como digresiones, "pasos" o "casos historiales" "; hecho conocido, pero últimamente revisado con criterios diversos, según apuntaré luego. Este relato, cuyo arte y encanto invitan a la lectura directa, debe resumirse aquí: ha terminado el alzamiento de Gonzalo Pizarro contra el emperador y el victorioso Gasea premia y castiga ${ }^{5}$. Rodrigo Niño, hijo de Hernando Niño, regidor de Toledo, obedece a una carta paterna que lo llama a tomar posesión de un mayorazgo "que un pariente suyo le dejaba'. Dada la calidad personal de Rodrigo y su lealtad a la Corona, el presidente Gasea aprovecha para mandar a España, bajo la custodia de Niño, a ochenta y seis galeotes, gonzalistas condenados. El presidente ofrece un premio, pero no da guardas (o escasas). El viaje empieza bien; luego, ya en Panamá, los condenados empiezan a huir. Hay en el Caribe un incidente con un corsario, a quien Niño engaña con un ardid. Los presos continúan escapándose y al entrar a Sevilla sólo le queda uno. Exasperado, Niño lo insulta, le da de puñadas y lo despide, prefiriendo afrontar solo lo que ocurra. En la Contratación lo enjuician y condenan a servir en Orán y a no poder volver a Indias. Rodrigo apela ante Maximiliano y tiene "padrinos". El buen príncipe lo absuelve en hermosa escena.

El cronista Montesinos, autor poco afecto a Garcilaso, mues-

"Mi opinión en "En torno a la prosa del Inca Garcilaso", Nuevo Texto Crítico, Stanford, p. 218; véanse notas 7, 8 y 10.

${ }^{5}$ Para la pacificación de don Pedro de la Gasea y su política tras el gran levantamiento pizarrista abundan documentos y crónicas; entre las aquí citadas, cf. Diego Fernández el Palentino, Historia del Perú, Madrid, 1571, parte I, lib. II; dispuso de abundante información. 
tra aceptar los hechos ${ }^{6}$. Los sitúa en 1548. Llegarían a España en 1549.

Se ha extendido el interés por los "pasos" en la obra del Inca Garcilaso". Eran digresiones narrativas que cumplían una función literaria en el conjunto de la obra. Esas mudanzas temáticas, bueno es subrayarlo, divertían y realizaban también el ideal de la variedad, $\tan$ importante entonces como el de unidad. A veces lo hacía el Inca para dar respiro, o para cambiar de tono, cuando no para crear un suspenso, al modo de algunos autores épicos de su devoción, como Ariosto o Ercilla. Asimismo, por tener pretexto para referir una anécdota atractiva. Los "pasos" aparecen también en textos breves, como la Genealogía de Garcipérez, cuyo tema es una monótona relación familiar: allí encuentra modo de insertar la famosa traición de Beltrán Duguesclin. Si esto podía ocurrir, como ocurría, en el arte histórico (parte, como se sabe, de la retórica), ya apunté que igual se daba en el otro gran reino del arte narrativo, la epopeya. Distinta cosa serán en Garcilaso las "fábulas historiales" 8 , como llama a los mitos indígenas que obligadamente debía incluir, pero señalando que no creía ingenuamente en ellos.

Hoy existe una peligrosa tendencia a suponer que estos "casos" son ficciones y ni siquiera se advierte hasta qué punto; no existiendo pruebas todo queda en suposiciones, así vengan de un estudioso respetado como José J. Arrom. El problema de la veracidad en Garcilaso es sumamente arduo y, contra lo que suele imaginarse, pobremente estudiado ${ }^{9}$. Más tarde el profesor Arrom, obrando con rectitud, modificó sus primeras ideas, pero creyendo que Garcilaso intercalaba "cuentos", a más de leyendas y anécdotas. A mi entender es muy claro el que el Inca dice "cuentos", para referirse a anécdotas históricas ${ }^{10}$.

${ }^{6}$ Fernando de Montesinos, Anales del Perú (ms. de 1642), ed. Víctor M. Maúrtua, Madrid, 1906, t. 1, p. 191. Montesinos no era seguidor habitual del Inca.

7 Véase nota 1; también, José J. Arrom, Certidumbre de América, $2^{\mathrm{a}}$ ed., Gredos, Madrid, 1971, pp. 27 ss; EnRIQUe PuPO-WALker, Historia, creación y profecía en los textos del Inca Garcilaso de la Vega, J. Porrúa Turanzas, Madrid, 1982, cap. 5. Pueden darse otros textos de criterio semejante.

${ }^{8}$ Por ejemplo en Comentarios reales (en adelante $C R$ ), Lisboa, 1609, lib. I, cap. 18.

${ }^{9}$ Lo indico en "Garcilaso Inca jura decir verdad", Crítica Hispánica, Pittsburgh, 10 (1988), pp. 21 ss. Cf. nota 48.

${ }^{10}$ Un ejemplo claro de cuento que usa Garcilaso como "anécdota histó- 
Volviendo al "paso" del capitán Niño (que Arrom no trata), su fama aumentó por haberlo incluido Ángel Rosenblat en un delicioso manojo de narraciones breves de Garcilaso ${ }^{11}$; de allí se reprodujo. Antes ya había figurado en las antologías de Riva-Agüero y otras. Atiende brevemente el episodio el profesor Enrique PupoWalker y aunque escribe con prudencia, lo incluye en un capítulo dedicado a "La ficción intercalada" 12. Así se trate de relatos que fuesen ficticios en su función (lo cual no se dilucida), la duda subsiste y el problema sigue sin enfocarse según la metodología histórica. Siento diferir de Pupo-Walker, a quien se debe un esfuerzo para apreciar al Inca Garcilaso. Sobre el pasaje de Niño con el corsario, recuerda la frecuencia narrativa de tales incidentes, hasta en novelas bizantinas. Interesante observación, que apunta sin excesos.

Se ha ido formando así una corriente que ahora prolongan otros. Algunos dan por sentado el carácter limitadamente histórico de las obras del Inca, o bien prefieren ignorar la cuestión suponiendo la primacía (o de hecho exclusividad) del aspecto literario del autor. No es asunto demostrado y origina sorpresas.

Hay tras estas actitudes ciertos asuntos teóricos largos de discutir y aquí inapropiados. Ahora me limito al famoso y enigmático episodio de Rodrigo Niño en cuanto a su posible verosimilitud o veracidad, con las consecuencias (históricas y literarias) que esto supone.

\section{El CAPITÁN NiÑO SEGÚN CRONISTAS}

Entre los cronistas de las guerras civiles peruanas que se imprimieron temprano (y los manejó Garcilaso), Niño aparece varias veces como persona claramente identificada. Primero figura en el contador Agustín de Zárate, 1555, luego en 1571 en Diego Fernández el Palentino ${ }^{13}$. El Inca Garcilaso recoge esas noticias de di-

rica" en Historia general del Perú (en adelante HGP), Córdoba, 1617, lib. viI, cap. 7.

${ }^{11} \mathrm{El}$ paso de Rodrigo Niño aparece en HGP, lib. VI, caps. 8-9. Gf. ÁNgel Rosenblat, La primera visión de América y otros estudios, Ministerio de Educación, Caracas, 1965. Apareció anteriormente como artículo.

12 E. Pupo-Walker, op. cit., cap. 5.

${ }^{13}$ Cf. Agustín de Zárate, Historia del descubrimiento y conquista del Perú, Anvers, 1555, lib. V, cap. 10; EL PALENTINo, op. cit., parte II. 
versos capítulos y también en algunas páginas sobre los galeotes. De todos tres, el Inca comprendido, han abundado y abundan ediciones, indispensables de aprovechar. Zárate estuvo presente durante el alzamiento gonzalista, desde su estallido, y hasta anduvo bastante comprometido en algunos hechos; tiene valor de testigo: o directo o contemporáneo. El Palentino, aunque posterior, dispuso de excelente documentación sobre la guerra gonzalista, y para el alzamiento de Francisco Hernández Girón, unos años más tarde, es la fuente principal ${ }^{14}$. Adelantemos que nada dicen sobre el lance de los galeotes, lo cual no sorprende por ser asunto menor dentro de aquel gran cuadro. Interesan en cambio, para mí mucho, las noticias sobre Niño, no sólo por lo autorizadas sino porque es capital verificar si, como veremos, concuerdan o difieren del personaje presentado por el Inca.

Al referir la rebelión pizarrista contra el virrey Núñez Vela (y las célebres ordenanzas), Garcilaso presenta por primera vez a Rodrigo, dentro de un largo pasaje en que se basa a la vez en Zárate y el Palentino ${ }^{15}$, quienes concuerdan "casi por las mismas palabras". Aunque el entrecomillado de algunas ediciones modernas puede llevar a error, acudiendo a las ediciones originales se ve que las palabras que transcribe el Inca vienen del contador Agustín de Zárate:

Otro día llegó a Los Reyes Rodrigo Niño, hijo de Hernando Niño, regidor de Toledo, con otros tres o cuatro que no quisieron ir con Gonzalo Díaz. Por lo cual, demás de hacerles cuantas afrentas pudieron, les quitaron las armas y los caballos y vestidos, y así venía Rodrigo Niño con un jubón y con unos muslos viejos, sin medias calzas, con solos sus alpargates y una caña en la mano, habiendo venido a pie todo el camino. Y el Visorrey le recibió con grande amor, loando su fidelidad y constancia ${ }^{16}$.

Estas palabras se leen idénticas en Garcilaso ${ }^{17}$. Varios puntos merecen señalarse. El contador sabe, por ser notorio y persona

${ }^{14}$ Cf. Raúl Porras Barkenechea, Los cronistas del Perú, 1528-1650, y otros ensayos, ed. F. Pease, $2^{\mathrm{a}}$ ed., Banco de Crédito del Perú, Lima, 1986, pp. 225 ss. Es opinión aceptada modernamente por todos, inclusive por Juan Pérez de Tudela, editor de esta crónica y estudioso de estas guerras.

${ }^{15} H G P$, lib. IV, cap. 11 ; la referencia a Zárate y $E_{L} P_{A L E N T I N O}$ la da el Inca al empezar el capítulo.

${ }^{16}$ Zárate, Historia. . , lib. V, cap. 10.

17 EL PALENTINo omite este incidente de Niño. 
conocida, la patria toledana y deja en claro su posición social con la mención del regidor. Todo parece exacto, aunque lamento no conocer el registro de Niño en la Contratación, para reafirmar los datos ${ }^{18}$. ¿Por qué Zárate los da, cosa rara en él, pero tampoco obligada? Pienso que había una razón: justamente por entonces figuraba en Lima (donde abrazó la causa de los revoltosos), el licenciado Rodrigo Niño, hombre rico e importante, quien jugó su propia carta en esa guerra. El licenciado, como veremos, era hermano de Hernando, el regidor, y por tanto tío carnal de su homónimo. El contador Agustín de Zárate, oficial del rey, tenía que saber esos hechos en tierra donde no había muchos españoles destacados. De otro lado, el elogio que el virrey hace de la fidelidad de nuestro Rodrigo Niño será el mismo que repite Garcilaso y esta virtud se dirá que influyó en la decisión del presidente Gasea de confiarle a esos condenados. Hay bastante más: un regidor del cabildo de Toledo tenía por fuerza que hallarse bien relacionado. Según el episodio, Niño tuvo "padrinos", y alguien debió de abrirle las puertas del príncipe Maximiliano. Seguimos sin pruebas directas sobre aquel paso, pero las hay circunstanciales.

Leídos modernamente, dichos cronistas pueden confundir con esos homónimos. Así ocurrió con historiador tan influyente como el general Mendiburu, quien los da por una misma persona y piensa que el capitán fue un tejedor que cambiaba de partido ${ }^{19}$. Apuntemos que Ricardo Palma se basa en Mendiburu para escribir una breve y poco feliz tradición, "Niñería de Niño". Las acusaciones sólo valen para el licenciado (quien más tarde llegó a alcalde de Lima).

Más sobre la actuación militar: el Palentino informa en el libro II sobre Niño, quien figura como capitán en la campaña contra Hernández Girón. Esto ocurrió a fines de 1553 y en 1554, tiempo después del famoso episodio. En general el Inca sigue aquí al $\mathrm{Pa}$ lentino, aunque éste ofrece un par de noticias más. Cuando los oidores, en ausencia del virrey, deciden formar el ejército, entre los jefes se contarán el alférez general Lope de Zuazo, y entre los ca-

18 Cf. Cristóbal Bermúdez Plata, Catálogo de pasajeros a Indias durante los siglos XVI, XVII y XVIII, Madrid, 1940-1946; en este repertorio, utilísimo aunque incompleto, no aparece Rodrigo Niño; eso nos priva de noticias complementarias, que quizá cabría ampliar en los asientos originales del AGI.

19 Cf. Manuel de Mendiburu, Diccionario histórico-biográfico del Perú, Lima 1885 , t. 6, s.v. Niño. Además de seguir a Garcilaso sobre los galeotes, informa que fue tres veces alcalde limeño (cierto para el licenciado); yerra al leer el pasaje del Inca sobre las "puñadas" o "puñaladas" que dio al galeote. 
pitanes de infantería Diego López de Zúñiga y Rodrigo Niño; añade luego a Juan Maldonado de Buendía; Garcilaso olvida a éste, pero apunta: "Rodrigo Niño, el de los galeotes". Significativo" Son nombres que convendrá tener presentes. Ya en plena campaña, cuando el maese de campo Pablo de Meneses ejecuta una difícil operación, acude a tres compañías, una la de Niño; esto no lo consigna el Inca. Ambos cronistas hablan de cierto diálogo que Niño tuvo con el jefe rebelde Piedrahita, a quien se le ofrecía perdón real; Garcilaso explica lo hablado ${ }^{21}$. Más importancia tiene algo que cuenta el Palentino, cuando ya el ejército de Girón flaqueaba, cerca de Pucará. Al disponerse las fuerzas reales para entrar en batalla, iban "en el avanzada el capitán Juan Tello y Rodrigo Niño" 22. Una actuación a las claras destacada y la registra una fuente imparcial.

Recordemos ahora que, según el Inca, el fallo del juicio en la Contratación sevillana condenaba a Rodrigo, entre otras cosas, a no retornar a las Indias: añade que el reo fue absuelto por el príncipe regente, quien concedió que "podáis volver. . . cuando quisiéredes". Añade Garcilaso que "años después se volvió al Perú", donde "largamente" contaba lo ocurrido. Muy posible, pues aquí lo vemos.

Se acumulan así detalles que invitan a pensar que si aquel episodio era ficticio, lo fue de manera minuciosamente elaborada.

\section{Para "Desaguar la tierra"}

Además de noticias tempranas de cronistas, existen documentos de época donde aparece el capitán en vivo y replicando preguntas. Dentro de lo publicado hay textos conocidos (aunque no recordados para el caso) y otros más raros. Sobre eso hay un expediente inédito en el Archivo de Indias. Todo lo cual, llanamente observado, continuará esclareciendo el caso, al menos parcialmente.

En el valle de Chincha, el lunes 7 de mayo de 1554, don Pedro Portocarrero acepta el cargo de maese de campo contra $\mathrm{Gi}^{-}$ rón. Se hizo reseña: quinientos treinta hombres y venticuatro de ellos entraron en consulta. Consignados sus nombres sin mucho

${ }^{20}$ Palentino, op. cit., parte II, lib. II, cap. $28, \mathrm{f} .58 \mathrm{v}$; InCA Garcilaso, HGP, lib. VII, cap. 7.

${ }^{21}$ PaLENTINO, ibid., caps. 49 y 51, ff. 99 y 104.

22 Ibid., cap. 53, f. $110 \mathrm{v}$. 
orden, entre los primeros estarán, bien diferenciados, "el licenciado Rodrigo Niño" y "el capitán Rodrigo Niño" 23. (También figuran el padre del Inca y varios parientes suyos.) Cuando aparecieron estas noticias de los homónimos, ya se habían publicado el Diccionario de Mendiburu y la tradición de Ricardo Palma.

De mucha mayor sustancia es cierta carta a Su Majestad del virrey primer marqués de Cañete, bien conocida por los estudiosos. Está fechada en Lima, 3 de noviembre de 1556, concluido ese desdichado alzamiento, pero todavía insegura la Corona de la pacificación de la tierra. Urgía echar las bases de una administración firme. Se respeta al primer marqués, estadista sagaz, por mucho que ciertas medidas suyas resultaran abusivas, según aquello que acabó llamándose razón de estado ${ }^{24}$. Durante años y decenios, las guerras y la ambición atrajeron al Perú a muchísimos soldados, y su exceso promovía revueltas. El marqués envió fuerzas a Chile al mando de su hijo don García (allí iba Ercilla); promovió "entradas" o expediciones; desterró a muchos, y también a quienes con justicia pretendían recompensa: uno de ellos el capitán Rodrigo Niño. En "cuatro meses que ha que vine", se jactaba el virrey, logró que "se desaguara" la tierra. Todo lo dice sin escrúpulo. Dada la incompetencia de los oidores, escribe, acude a un "pesquisidor" y "me aprovecho del doctor Cuenca y de un alcalde de corte que yo truje, Chirinos". Disponía así de una Audiencia paralela.

En cuanto a las pretensiones de ciertos capitanes y soldados, había algo con lo que la justicia y los usos andaban reñidos. El soldado que luchaba sin paga, como hijodalgo, esperaba natural recompensa. Ya en el Perú había poco que repartir y sobre eso las autoridades querían rentas para sus protegidos. Acabada la guerra contra Girón, hubo distinguidos capitanes y soldados que reclamaban premio según sus hechos y calidad. Mal momento: Su Majestad acababa de escribirle al virrey Cañete que "no reparta los repartimientos que hallará vacos y vacaren"; el virrey aprovechó la advertencia, aunque algo adjudicó según su parecer. Existía otra circunstancia, la conocida política de casar a soldados con mujeres españolas dizque para aquietarlos: sobre eso hubo siempre diversos y explicables reparos. Había mujeres em-

${ }^{23}$ Palentino, op. cit., ed. Lucas de Torre, Madrid, 1913, t. 2, apéndice 1, p. 289; la obra no alcanzó a imprimirse completa.

${ }^{24}$ Gobernantes del Perú. Cartas y papeles, ed. Roberto Levillier, Madrid, 1921, t. 1, pp. 292 ss. 
parentadas con las autoridades; también viudas de encomenderos, con posesión de tierras. Cañete procuró matar dos pájaros de un tiro, dando buenas rentas a la vez que apoyaba la política matrimonial. Más de una vez Cañete o los oidores forzaron la mano sin éxito ${ }^{25}$. Derrotado Girón, había un grupo de capitanes y soldados viejos que exigían recompensa. Eran los vencedores, su decepción crecía y se hallaban alborotados. Unas palabras de la carta del virrey parecen indicar que hubo contra ellos indicación adversa del escuchado Pablo de Meneses.

Finalmente Cañete decidió someterlos. Escondió poderosa guardia y envió "a llamarlos uno a uno" a palacio; luego, conforme entraban, "los metían en una pieza que está junto a mi aposento". Poco leal astucia: "allí los desarmaban", al parecer sin ninguna explicación. "La guarda de pie y de a caballo" estaba apercibida, y "dentro de una hora los llevaron a todos a la mar, a metellos en una nao", como presidio. Cañete deseaba impedir una revuelta: por cuanto dice, no se sabe si real o posible, ni se conoce su magnitud. Sospechas y algún informe bastaron, pero los nombres que ya conocemos dicen mucho:

Vinieron Diego López de Zúñiga, capitán, y Rodrigo Niño y Juan Maldonado, asimismo capitanes, y Lope de Zuazo, alférez general que fue en lo de Francisco Hernández, y los dos Palomeques y [Juan de] Palomares y Gonzalo Silvestre y Blas de Merlo.

Estos últimos eran soldados; luego Cañete añade al "capitán Juan Porcel y a Villafuerte". Aclara que "esto se hizo a diez de octubre" y que los amigos o quizá seguidores de los presos "quedaron espantados y asombrados". La carta no habla de ningún proceso, que en rigor no lo hubo, sino una rapidísima información, pero la apostilla reza: "Los capitanes que envío presos". Eran parte importante y aun cabeza de las fuerzas leales que sirvieron a Su Majestad.

Antes de dar tamaño paso, el virrey, primer marqués de Cañete, recibió y habló con algunos quejosos. Tras unas palabras acaloradas con el antiguo soldado Palomares, Cañete, según es-

${ }^{25}$ Escribe el Inca: "Y muchos de los pretensores les señalaron las mujeres con que habían de casar"; el virrey "las tenía a todas por muy honradas y honestas, pero muchas dellas no lo eran" (HGP, lib. VIII, cap. 7). Tal política matrimonial tenía que afectar al noble mestizo, cuyo padre acabó casado con española; trata esto Aurelio Miró QueSAda, El Inca Garcilaso, $3^{\text {a }}$ ed., Madrid, 1971, cap. 3. 
cribe, trató con el capitán López de Zúñiga, a quien juzga importante y de "mejor casta". Le propuso una boda de compromiso, que el capitán rechazó, y se mostró herido en su honra. El segundo fue Rodrigo Niño, de cuya distinción no habla, aunque era conocida. Escribe el virrey:

El capitán Rodrigo Niño había dicho muchas veces que los oidores le daban un repartimiento que le rentaba más de seis mil pesos, que se llamaba Achacachi, que era de Joan de Illanes y que no lo había querido.

Sólo a estos dos capitanes se refiere expresamente. Apunta el temor de una revuelta, sin pesar para nada los méritos de los pretendientes, ni su conducta anterior. Cierto que Niño tenía altas exigencias, como consta en otro documento, pero sus servicios eran claros.

El propio Palentino, cronista áulico, apunta (y transcribe Garcilaso) que "so color de fiestas y regocijos" el virrey "recogió en su casa" muchas armas; después prendió "en su propia casa, con buena maña", a los que pedían remuneración de sus servicios. Los mandó a España "publicando enviar a unos para que Su Majestad allí los gratificase [...], porque en el Perú no convenía"; y a otros castigó con destierro. Cuenta el cronista ${ }^{26}$ que algunos aconsejaron enviar información "de sus culpas", así de palabra como de obra, pero el virrey prefirió abstenerse. La intención de Cañete queda clara en su carta y tiene confirmación. La prisa con que actuó lo demuestra. Para Garcilaso, el Palentino ofrece "pasos de historia que conviene declarar" $y$ "diremos historialmente el suceso de cada cosa". Tras puntualizar algún caso trata el asunto de los matrimonios forzados (verdad probada), y aun levanta dudas sobre la virtud de algunas damas ${ }^{27}$. Bien pudo ser. $Y$ añade el Inca: "Fueron treinta y siete los que prendieron y embarcaron, que eran los más calificados y más notorios en el servicio de Su Majestad'. . Dos de ellos, Gonzalo Silvestre, grande amigo e informante : del Inca, y el capitán Rodrigo Niño.

${ }^{26}$ PALENTINo, parte II, lib. III, cap. 2, f. 120 r; habré de volver sobre el pasaje. Para la relación del cronista con el virrey, cf. Porras Barrenechea, loc. cit.

${ }^{27}$ Cf. nota 25. Advirtamos que muchos documentos confirman la exactitud del Inca en varias materias aquí tratadas. 


\section{Ante El doctor Cuenca}

El virrey se ufanaba de la prontitud con que actuó, lo cual supone en estos casos cortos escrúpulos; eso no sólo se lo escribe a Su Majestad sino también al duque de Alba, en texto menos conocido ${ }^{28}$. En breve carta fechada en Lima, a último de febrero de 1557, dice que es tierra buena, pero inquieta, aunque algo ha hecho, “pues serán los ahorcados, degollados y desterrados della más de ochocientos después que vine. Plega a Dios que aproveche". Es evidente que simplificó procedimientos, así para prender a sospechosos como para abrir instrucción. Ya le contó al emperador el propio virrey cómo eludía a algunos oidores y usaba al doctor Cuenca y a otros de confianza. Así lo veremos en una información que abre Cuenca a un grupo de los beneméritos pedigüeños. Si Niño y compañeros fueron detenidos el 10 de octubre, la información se abría, obtenidos los testigos y hechas las pesquisas, el 16 de octubre de 1556, cumpliendo con la cédula virreinal del 14 . En dos días todo estaba listo para empezar, y como no era proceso se podía llegar pronto a resultados. El auto final del virrey fue del 2 de noviembre, a los dieciocho días contados de la orden. El expediente se halla en el Archivo de Indias y echa luz sobre el caso, sobre Niño y - aunque aquí no nos detengamos en este personaje- sobre Gonzalo Silvestre ${ }^{29}$.

Para este expediente sólo llamaron a un grupo de diez, tres capitanes y siete soldados, sin duda los más importantes para los consejeros de Cañete. Se echa de menos al alférez general Lope de Zuazo y es probable que hubiese otras "causas", por llamarlas así. Nueve de los diez, incluyendo a Villafuerte, figuran en la carta del virrey a Su Majestad. Nombra también a Juan Porcel, capitán conocido pero que no aparece en este expediente.

Comparecieron tres capitanes: Diego López de Zúñiga, Rodrigo Niño y Juan Maldonado de Buendía. Los siete soldados eran Diego de Palomeque de Meneses, Rodrigo Palomeque, Blas de Merlo, Gonzalo Silvestre, Miguel Rodrigo de Villafuerte ${ }^{30}$, Juan

${ }^{28}$ Documentos escogidos de la casa de Alba, "los publica la duquesa de Berwick y Alba", Madrid, 1891, p. 216.

${ }^{29}$ AGI, Justicia, leg. 1088, núm. 2, ff. 1-50; va del 14 de octubre al 2 de noviembre de 1556 .

${ }^{30}$ Parecería que debe ser Rodríguez de Villafuerte, apellido destacado en el Perú, pero en el auto final de Cañete se lee "Miguel Rodrigo de Villafuerte"; en la carta el virrey lo llamaba "Villafuerte" a secas. Puede ser así. En 1554, Francisco Rodríguez de Villafuerte era alcalde del Cuzco y sufrió el atro- 
Chacón de la Maza y Alonso Palomares. Sólo Chacón de la Maza (cuyo nombre no veo claro) está ausente de la carta del virrey. Eran, pues, los principales.

El mañoso sistema seguido por Cuenca no obligaba a interrogatorio formal ni llevaba sentencia directa, sino acababa en un auto virreinal que consistía en lavarse las manos y remitirlos a $\mathrm{Se}-$ villa, para que allí se les juzgase. De hecho quedaban rapidísimamente desterrados e iban "presos", como lo dice la apostilla de la carta citada.

Para esto se habían reunido en un santiamén trece testigos, en su mayoría gente de poca figuración, salvo el capitán Diez y el doctor Saravia, quien por cierto había tenido que ver en las disputas con estos pretendientes. Saravia representa el punto de vista de los oidores. Los testimonios son en gran medida habladurías callejeras y chismes. Si a cada soldado español de entonces lo enjuiciaran por quejas y amenazas, no hubiera habido con qué formar un tercio. Los cargos, pues, no se sustancian sólidamente, y por no ser proceso todo podía registrarse: palabras diversas y lo que quizás podía llevar a verdaderos indicios.

Después seguían las “confesiones", que en rigor eran más bien declaraciones, con mucho de respuesta a los "testigos". No todos quisieron confesar: por ejemplo no lo hizo Gonzalo Silvestre, pero sí Rodrigo Niño. Afortunadamente, pues en lo que dice se muestra de cuerpo entero y complementa noticias. Sus respuestas guardan relación, en buena medida, con el interrogatorio de testigos ${ }^{31}$.

Sobre lo principal, las señas de rebeldía, Rodrigo Niño, "natural de Toledo", nada reconoce; lo que le achacan o imputan no tiene firmeza. De otro lado, aceptar insinuaciones vagas sería un absurdo: "que se juntó con los demás capitanes y amigos y soldados, y todos juntos fueron muchas veces a los acuerdos a fatigar a los oidores que repartiesen la tierra [...], y que sobre ello hablaban desacatadamente"; y hasta "juraban a Dios que si no se la diesen y repartiesen, que ellos se la tomarían". Cuentan que Niño una vez "dijo que los señores oidores eran mayores traidores que Francisco Hernández", quien "les quitaba las vidas, y

pello de las huestes de Girón; cf. Diego de EsQuivel y NAvia, Noticias cronológicas de la gran ciudad del Cuzco, ed. Félix Denegri Luna, Lima, 1980, t. 1, p. 172; como se sabe, don Feliciano Rodríguez de Villafuerte, hijo segundo del anterior, fue a estudiar a España y mantuvo correspondencia y finezas con Garcilaso, que comentan sus biógrafos (HGP, lib. VII, cap. 22).

${ }^{31}$ AGI, loc. cit., ff. 44-46. 
ellos la honra y hacienda". Falta saber qué eran desahogos (bastante justificados) y qué ideas serias: en cuanto a reunirse los̀ demandantes, tras la victoria que ellos ganaron por el rey, nada parece más natural. Hasta le preguntaron a Rodrigo si “juraba a Dios que habían de matar al doctorcillo, diciendo por el doctor Saravia, porque impedía que no se repartiese la tierra". Cierto que Niño tenía sus problemas con ese "doctorcillo", pero no cabe igualar frases airadas con amenazas dichas por quien tuviese turbios antecedentes.

De paso aparece una noticia de interés. Cuenta el "confesante" haber ido un mes a cavar una gruta por "alguna riqueza", en compañía del "licenciado Rodrigo Niño, su tío". Ante la codicia y el obligado secreto, ambos hidalgos de Toledo no vacilan en trabajar con sus manos: hecho que en Indias solía darse más que en la Península (era asunto de honra). Este común secreto muestra la relación familiar, fuese mayor o menor, que se daba en hombres muy distintos. Anduvieron juntos cavando un mes. Probablemente vivían lejos: el licenciado era encomendero limeño, y el capitán parecía más relacionado con la región cuzqueña o del sur andino. Algo más de este parentesco lo sabremos aquí.

En este interrogatorio-confesión lo más saltante, igual que en la carta del virrey, será lo tocante a repartos. A Niño le preguntan "si es verdad que ha dicho que juraba a Dios que aunque le diesen veinticinco mil pesos de renta, no se contentaría con ello ni lo había de tomar". El capitán niega, pero insisten: "si es verdad que en cumplimiento de una cédula de Su Majestad o la Audiencia le envió a decir que tomase indios que eran de Juan de Illanes y no los aceptó". Ya Cañete había movido el tema. La respuesta del capitán tiene particular interés:

Dijo que es verdad que se los daban los dichos señores e oidores los indios de Juan de Illanes, vecino que fue de Pueblo Nuevo [La Plata] ${ }_{{ }^{32}}$ con mil pesos de pensión para dar a Bernardino de Loaisa. E que este confesante anduvo negociando con el doctor Saravia que le quitasen la dicha pensión y que tomaría los dichos indios.

El capitán parece tener conciencia de sus méritos y deja traslucir algo que, a mi ver, más que el interés de un pretensor común, es la ambición de un hombre importante que quería ir a más. Sus palabras mostrarán su carácter:

32 "Pueblo Nuevo o Villa de la Plata" escribe el propio Cañete. 
...E que tratándose este negocio le habló el licenciado Santillán [oidor], y el factor Bernardino de Romaní, sobre que se casase con Doña María, sobrina del licenciado Altamirano, e que si le hobiesen de dar ocho mil pesos de renta le darían dieciséis, y si doce, veinte y cuatro, y que suspendieron el dar los dichos indios por esta causa, algunos días. Y que no le dieron éstos ni otros, que como este confesante no aceptó el casamiento, se quedo ansí.

La versión de Rodrigo Niño es enteramente verosímil, porque eso venía ocurriendo entonces, según vimos. Aunque estuviese en posición ingrata, el capitán le habla a Cuenca con desenvoltura y aplomo. Y hasta llega a algún desafiante sarcasmo. Parece hombre altivo, amigo de su honra. Ya al tratar con el virrey se había mostrado firme, pero de esa conversación las noticias que han llegado son más breves. Aquí nada calla. Quizás la sobrina del oidor Altamirano fuera una de esas españolas no muy bien vistas ${ }^{33}$. Aquel insistir por ella del factor Romaní llama la atención, y $\mathrm{Ni}$ ño no oculta cierto humor al contarlo.

Vimos que ya se le había acusado de proclamar que no aceptaría sino altas recompensas. Siendo hidalgo e hijo de un toledano distinguido, hay que comprender que Rodrigo no vendría a Indias como un pobre escudero de capa y rodela. Quería tierras y para eso había luchado. Otra pregunta resulta ilustrativa:

Si es verdad que dijo: cuerpo de Dios, que al cabo de tanto tiempo que estoy en la tierra no tenga en ella ninguno [sic] de tierra, juro a Dios que ha de venir tiempo que tengo de tener una tapia.

Era un juego de palabras con un tanto de humor negro, pues la tapia era una pequeña unidad de medida terrestre. Cuenta entonces el capitán cómo fueron y "cavaron una gruta, porque les dijeron había allí alguna riqueza". Sería una huaca, y allí fue junto con el tío licenciado. Trabajaron un mes y "este confesante le dijo entonces" a un compañero que le aseguraba "que no tengo para hacer un bodoque, pero placerá a Dios que algún día tenga para hacer una tapia". Mostraba, pues, gran empeño de alcanzar tierras de encomienda. Quien conozca los hechos entenderá que a este capitán, a un tiempo tenaz y colérico, lo movía una razón

${ }^{33}$ Verifíquese que estas damas eran parientes de los oidores, y de varios, y tenían el apoyo personal del virrey. Justamente los oidores habían dirigido torpemente la guerra contra Girón, que ganaron los pretendientes. Hay más casos de estos abusos, y alguno veremos. 
personal: el licenciado no había sido un modelo de lealtad a la Corona, ni se había distinguido tanto como su sobrino en lo militar, al menos por cuanto se sabe.

Resultado final, harto previsible: con pasmosa celeridad burocrática, el virrey escribe un auto el 2 de noviembre, "habiendo visto esta información las que vanijuntas, que pasaron ante el mariscal Alonso de Alvarado", por lo que Cañete dispone no un explícito destierro, sino que "vayan a España"' esos diez a la Casa de Contratación, donde, vista "la dicha información", no proceso, presente a Su Majestad a los diez citados y (lavándose el virrey las manos) allí se "provea" lo debido. No dice el auto que vayan presos; pero sí da detalle de haber guarda, con sus responsables. Turbia leguleyada, así la hiciera un gobernante de subidos méritos ${ }^{34}$.

Todo se resume en el título de un capítulo del Inca, harto explícito y, hasta donde sé, veraz:

Lo que el visorrey hizo con los pretendientes de gratificación de sus servicios; cómo por envidiosos y malos consejeros envió desterrados a España treinta y siete de ellos ${ }^{35}$.

Vimos que el Palentino, adicto al marqués de Cañete, presenta los hechos del modo más moderado, hasta tergiversarlos. El Inca Garcilaso, en cambio, aunque elogia aciertos posteriores del virrey ${ }^{36}$, primero censura y luego no calla (como el Palentino) la buena suerte final de aquellos capitanes y soldados:

Volviendo a los pretensores de repartimientos de indios [...] que venían desterrados a España, decimos que llegaron a ella bien fatigados de la pobreza y hambre que traían. Presentáronse en la corte, ante la Majestad del rey don Felipe Segundo; [ . . ] les consoló con hacerles mercedes en Indias a los que quisieron volver a ellas. [...] Y a los que quisieren quedarse en España les hizo mercedes conforme a sus servicios y calidad, [...] como yo lo hallé cuando vine a España, que fue poco despiées ${ }^{37}$.

${ }^{34} \mathrm{El}$ brevísimo y malicioso auto final, en AGI, loc. cit., f. 50 ; en cuanto a las "entradas" para "desaguar" la tierra, ya se sabe que alguna acabó en manos del tirano Lope de Aguirre.

${ }^{35} H G P$, lib. VIII, cap. 7.

${ }^{36}$ Aunque no oculte reticencias, Garcilaso no ve con malos ojos la ida de Sairi Túpac al Cuzco y le complace el bautizo (HGP, lib. VIII, caps. 10-11). Con todo, no creo a Garcilaso resuelto partidario de Cañete.

${ }^{37} H G P$, lib. VIII, cap. 13. La defensa pudo complicarse. Silvestre presentó información de servicios en Valladolid, 1558 (AGI, Patronato, 101, ra- 
Uno de los injustamente desterrados, dice, quien se quedó en Andalucía, fue Gonzalo Silvestre. El nombre de Rodrigo Niño jamás se menciona en estos lances. Cierto que Silvestre no sólo era íntimo amigo del Inca, sino bien conocido por sus lectores, desde La Florida. Por qué silenció a Niño es asunto que mueve a especulaciones; tampoco nos cuenta de su suerte, ni si volvió o se quedó.

En esta revisión no sólo se han logrado nuevas noticias sobre este pintoresco capitán. Si aceptamos la verosimilitud o verdad del episodio de los galeotes, la trasmisión al Inca ha quedado establecida. Con certeza mediante Gonzalo Silvestre, compañero del capitán no sólo en guerras, sino en prisiones, travesías y juicios; y aun es posible que Garcilaso alcanzara a Niño en España, tal como se topó con Silvestre. De cualquier modo, éste debió influir en el punto.

\section{Los Niño y el duQue de Alba}

Un volumen de documentos de la casa de Alba, impresos al parecer en edición no venal, que creo rara, contiene una inesperada serie de cartas entre el todopoderoso duque y el licenciado Rodrigo Niño. Su sobrino el capitán para nada figura allí, pero abunda información de interés ${ }^{38}$.

Cabe imaginar el revuelo que provocaría en Lima el saber que un grande entre los grandes como Alba se carteaba con un encomendero que ni siquiera residía en Los Reyes, sino en su finca de San Ildefonso, a veinticuatro leguas. Había muerto el regidor toledano don Hernando, quien le dejó un mayorazgo a su hermano el licenciado; la viuda doña Juana quedaba en necesidad, lo cual preocupaba al duque y lo movía a escribir. Ignoro lo que esto implicaba para el capitán, por entonces injustamente asendereado tras juicios, prisiones y práctico destierro.

De otro lado, cabe medir el aprecio en que tenía Alba a Hernando Niño y a su mujer, más allá de fórmulas de diferencia cortesana y pasando a hechos; en cuanto al licenciado, se dirige a él en buenos términos. Quedan una carta del duque y dos del li-

mo 18); en parte allí responde a ciertas acusaciones del expediente de Cuenca. Sobre la presencia del Inca en la Corte entre 1562 y 1563 , cf. A. MIRó QUESADA, op. cit., cap. 4. Trato el tema en "El Inca llega a España", RIM, 25 (1965), pp. 29 ss.

${ }^{38}$ Documentos escogidos de la casa de Alba, pp. 217-224. 
cenciado (virtuales duplicados para evitar pérdidas), pero hubo una anterior de Alba. El conjunto puede verse bastante claro: en julio de 1562, el duque envía al encomendero limeño una misiva, hoy perdida; su tenor se entiende por las dos respuestas del licenciado (verdadera negociación de mercedes y alegato de méritos propios y de su mujer). Esas respuestas son de noviembre de 1563 y enero de 1564. No llegaron pronto. La contestación del duque, última pieza conocida, es de Madrid, 10 de diciembre de 1564. En ella, aunque no se comprometa, da buenas esperanzas al licenciado, quien, en previsible rasgo de amor fraterno, acepta las sugerencias de Alba y ayuda a la viuda doña Juana con los frutos del mayorazgo, y acepta también ciertas sugerencias de verse mejorado en el Perú. Por lo demás, el licenciado era un colono a carta cabal, mucho más encomendero y negociante que autoridad (fue alcalde de Lima $)^{39}$ o guerrero, que parece haberlo sido muy ocasionalmente. Por entonces, claro está, esa actitud de vida no era muy típica en un noble hispano.

No oculta el licenciado su "gran contentamiento" al saber que el duque tuvo "a Hernando Niño, mi hermano, por tan servidor de su casa", y "haber sido muy señor de Hernando Niño, pues en su muerte se acuerda dél"; por cierto, el licenciado no queda excluido de tanta deferencia. En la carta que remite por otra vía insiste: le dio "gran alivio" ver que su excelencia "tomó a Hernando Niño por de su casa, y que agora en muerte le quiere favorecer, y a mi señora doña Juana y a mí hacernos merced" ".40 A su vez, el duque habla con visible aprecio "del señor Hernando", elogia la actitud del licenciado y añade que le "ha dolido tanto la soledad de la señora doña Juana" como corresponde a "su virtud" y ansias de cumplir con la memoria de su marido ${ }^{41}$. El buen predicamento de que gozaban los Niño en Toledo y con el propio Alba no admite dudas. Esta situación social, insistamos, suponía mucho. Puede explicar la buena fortuna del licenciado apenas llegado al Perú, no obstante su tornadiza actitud durante las guerras civiles: también, muy probablemente, el que su sobrino el capitán pudiera salir de apuros en España si necesitase ayuda. Es razonable pensarlo.

${ }^{39}$ Recuérdese que fue varias veces alcalde de Lima. Esto puede seguirse en los Libros de cabildos de la ciudad, que editaron B.T. Lee y J. Bromley.

${ }^{40}$ Documentos escogidos. . , p. 217 (primera carta al duque) y p. 221 (segunda carta).

${ }^{41}$ Ibid., p. 224. No todo era interés material en el licenciado, quien aprueba que su hijo rehusara una boda que le sugería el propio virrey (p. 218). 
La figura del licenciado como noble colono merece atención aparte; aquí interesa en relación con su sobrino, con quien contrasta en muchos puntos, aunque ambos se muestran adictos al mundo indiano.

Observación al margen: queda reafirmado el parentesco de tío carnal que tuvo el licenciado. Resultan improbables más confusiones de homónimos o bien un error de un contemporáneo como Agustín de Zárate, respecto al sobrino.

Al capitán Niño debió darle que pensar ver a su tío en muy alta posición, con tierra, riquezas y mereciendo consideraciones varias, habiendo prosperado sin perjuicio de algunos sesgos en su marcha política. No parecen haberse llevado mal, pues trabajaron juntos, pero hubo una de esas injusticias de la vida que impidió que el capitán, teniendo méritos, llegase muy lejos. De hecho, la actuación un tanto inquietante del tío licenciado empezó muy pronto. Según lo que cuenta al duque, debió haber llegado al Perú hacia 1541: tiempos de la guerra de Almagro el Mozo, previo asesinato del conquistador Francisco Pizarro. Da cuenta de ello a la Corona el licenciado Vaca de Castro, el 15 de noviembre de 1541: refiere que un mensajero almagrista "trujo solas dos cartas": una del rebelde "y otra del licenciado Rodrigo Niño, que agora vino de España, e luego fue a ser regente de don Diego" 42; allí Niño escribe "desvaríos", poco atinados para la causa real. Bien sabría manejarse luego, pues más tarde le refiere a Alba que "Vaca de Castro diome los indios que tengo"'. No los perdió en la guerra gonzalista, aunque consta en cronistas y documentos que perteneció a los rebeldes casi desde un principio. Primero fue procurador de la ciudad de Lima ante el infortunado y torpe virrey Núñez Vela: preso éste, el licenciado siguió en sus filas ${ }^{43}$. Cambió luego de bando, pero se queja al duque de que a Gasea "yo le serví muy bien en el castigo que hizo a Gonzalo Pizarro, y pagómelo mal"'. Al referirse a los gobernantes del reino y las concesiones que obtuvo de ellos, el toledano se muestra cazurro y habilísimo para llevar el tema por donde más le convenga. Nacido en buena cuna y en ciudad cortesana, tenía maneras, más algún estudio que lo llevó a obtener título. Sabe aprovecharlo todo con

42 Gobernantes del Perú..., t. 1, p. 36. Dudo de que Mendiburu aludiera a esta noticia, harto preocupante. La carta de Vaca de Castro es del 15 de noviembre de 1541 .

${ }^{43}$ Hay abundantes noticias en Zárate, op. cit., lib. V, y en $E_{L}$ PaLentiNo, op. cit., parte I. El licenciado, tempranamente, acudió como procurador de la ciudad de Lima ante el virrey Núñez Vela (Gobernantes del Perú, t. 2, p. 248). 
maña y buen estilo. Su situación es firme y hasta ha logrado buena boda con española, muy ligada a la tierra y que lo había fortalecido aún más en relaciones y en rentas. Era, dice, mujer principal, viuda, hermana del famoso obispo don fray Vicente Valverde. El presidente Gasea, le escribe Niño a Alba, prefirió mejorarla a ella. Por lo demás no era mala solución, por mucho que el licenciado afirme haber sido capitán de la guardia de Gasea. No era precisamente un puesto de riesgo.

Sobre sus hechos de armas, Rodrigo pasa como gato por las ascuas, aunque con vagas ponderaciones y quizá exagerando lo que hizo contra Girón, en lo cual efectivamente participó (aunque sin destacar como su sobrino, a quien no nombra). Por todo esto y por sus vaivenes en cuanto a fidelidad, rehuye cualquier expediente de información. Será explícito: "Yo no quiero enviar probanza de mis servicios, porque es cosa larga y enfadosa, y también porque es público haber yo servido mucho". Quizás. Y asimismo porque piensa que el duque "negociará este negocio mío por cámara" ${ }^{44}$. En cambio propone información relativa a su mujer.

No esperemos en este breve recuento de méritos hallar hazañas de espada o lanza, ni el lamentar heridas o la pérdida de un caballo. No iba a leer el duque de Alba proezas bélicas, usuales en los pretensores hispánicos. Una posdata muy interesante lo instruirá más bien de servicios estrictamente civiles. Habla sobre sus tierras de San Ildefonso:

Yo tengo este ingenio y otras haciendas, hanme costado mi sudor y trabajo, y estar en el campo trabajando; y esto no me lo ha dado Su Majestad, antes, por haberlo hecho en tierra nueva, me habrá de hacer mucha merced: que he abaratado la tierra de azúcar, como es público, y hecho seda, que nadie la ha hecho; y si he sido tan gran labrador que he abaratado la república de pan 18 años ha, [...] he tenido poco de honra, y en estas granjerías he gastado mucho ${ }^{45}$.

Al provecho, pues, y también a la honra por abaratar el pan y el azúcar, más cultivar seda. Tendría razón, pero sonaría a insólito.

${ }^{44}$ Admira la tranquilidad con que el pedigüeño le sugiere a Alba los caminos a tomar, pero necesitaba verse libre de acusaciones (Documentos escogidos..., pp. 219-224).

45 lbid., p. 220. 
EL MAYORAZGO

La correspondencia con el duque enriquece el conocimiento de estos Niño peruleros, puntualiza detalles, pero a la vez abre una incógnita, cuya importancia no cabe aún medir y sobre la cual escasean datos: ese mayorazgo propio que Hernando le deja en herencia a su hermano, estando vivo su hijo Rodrigo, el capitán. Según lo que refiere Garcilaso, había habido otro, que benefició justamente a Rodrigo el sobrino. Escribe el Inca:

Es de saber que en medio de estos sucesos llegó una carta a la Ciudad de los Reyes de Hernando Niño, regidor de la ciudad de Toledo, para su hijo Rodrigo Niño, de quien hicimos mención, [...] en la cual le mandaba su padre que, estando desocupado de las guerras contra Gonzalo Pizarro, se partiese luego para España, a tomar posesión y gozar de un mayorazgo que un pariente suyo le dejaba en herencia ${ }^{46}$.

Salvo error, pues, se trata de dos distintos, y no era raro en familias importantes el que recayese entre sus hijos más de uno de estos apreciadísimos legados, con sucesión. De ser cierta, como parece, la noticia del Inca, no sería imposible que el autor supiese (por Silvestre o por otro) de ambos mayorazgos.

Es necesario aquí recordar que la paternidad de Hernando la consigna Zárate, trayendo el punto como materia honrosa. Si se tratara de un hijo natural tendría menos sentido señalar quién era su padre. En cuanto a Garcilaso, presenta a Niño con el mayor respeto por su calidad. Pero, por una razón u otra, el hijo del regidor de Toledo no sucedió en ese mayorazgo.

Situemos algunos hechos: Gonzalo fue derrotado en 1548; tras juicio y viaje, los galeotes no debieron llegar a Sevilla antes de 1549. Luego vendría el juicio a Rodrigo. Nada se nos dice (tampoco era indispensable) de lo ocurrido con el otro mayorazgo, lo cual no significa que lo perdiese. Era bastante común el transferir dinero entre ambos lados del Atlántico; quizás esos haberes ayudaron al capitán, falto de encomienda aunque empecinado en tenerla.

Cuando Niño volvió, según Garcilaso, decía que "en toda España no halló hombre que me hablase buena palabra, ni de favor, si no fue el buen príncipe Maximiliano, [...] que me trató 
como príncipe"'. ¿Eran quejas contra los peninsulares, o contra su suerte, o hubo también disgustos familiares? Dicho así en general, no queda en claro, pero bien sabemos que Rodrigo tuvo "padrinos" ante el príncipe, vale decir, apoyo.

Las desventuras de Rodrigo continuaron y el virrey lo remitió a la Península a últimos de 1556; llegaría en 1557, acusado y causándole problemas a parientes y amigos. El proceso se alargó y Garcilaso lo atestigua personalmente. Hacia 1561 o 1562 todavía andaban estos peruleros en la Corte ${ }^{47}$. Mal momento, pues a juzgar por la correspondencia del duque, Hernando debió morir hacia 1561 o principios de 1562: precisamente.

Hay, pues, noticias bastante aproximadas, pero lo que sabemos del asunto en lo sustancial se reduce a especulación. Puede que el regidor se hastiara de los problemas de su hijo, además de acusaciones, así fueran injustas. Puede también que sencillamente Hernando juzgara que su hijo ya poseía un mayorazgo y le dejó el suyo a su hermano. Falta saber cuánto rentaban el uno y el otro. Imposible seguir con conjeturas.

\section{VERACIDAD Y VEROSIMILITUD}

En otros lugares de su Historia Garcilaso da por supuesta la verdad del paso historial de los galeotes. Eso no constituye prueba, pero tampoco puede pasarse por alto. Ya vimos que cuando nombra a Rodrigo dice "el de los galeotes". Hasta parecería que el Inca deseaba ligar la memoria de su personaje al donoso episodio y evitar la enojosa vuelta, remitido por Cañete. Más adelante escribe Garcilaso que en el Perú dejaron de usar la condena a galeras, en vista de lo que ocurrió con Niño ${ }^{48}$. O Garcilaso, pues, creía en la realidad del hecho o intentaba un cínico ardid para fabular: no sería caso único, pero aquí resulta insistente y aun extraño. Sobre todo porque nada de esto concuerda con la exactitud que hemos venido hallando en la exposición de rasgos y noticias del personaje. En su presentación, humana y moral, en las referencias familiares (y sus implicaciones), en el carácter altivo, fuerte, con señales de impulsivo e irónico. Sobre eso, la transmisión de la anécdota debió llegarle al Inca por Gonzalo Silvestre. No insistamos más.

${ }^{47}$ Cf. supra, texto y n. 37.

${ }^{48} H G P$, lib. VIII, cap. 2; ibid., lib. VI, cap. 29. 
La plena verdad del hecho depende de pruebas documentales, que ignoro. En cuanto a la verosimilitud, resulta claramente en favor de Garcilaso. Hablar del paso como ficción resulta ahora más arriesgado que hablar de verdad. Sin embargo, la elaboración literaria del suceso importa de todos modos: desde las primeras indicaciones sobre el capitán a la construcción del relato, con su inesperado clímax y feliz desenlace, todo expuesto con ritmo magistral (narrativo y de prosa), matices sutiles y sabiduría de escritor. Del mismo modo, la función del paso en la Historia sigue siendo igual.

Hace mucho lo digo: el Inca no es un cronista peruano típico sino un historiador humanista, preocupado también por la forma literaria y por los modelos. No revolvamos los nombres de estos historiadores, que llenan siglos, más los preceptistas. Situar a Garcilaso entre ellos parece aún muy difícil. Por fortuna no es aquí indispensable: recordemos simplemente a quienes, como Fox Morcillo o Páez de Castro, reclamaban la veracidad histórica aunque permitiendo la verosimilitud para llenar vacíos o ganar en pulso vital. No serán las normas exactas del Inca (y en cada obra), pero este criterio parece más próximo al autor que las ideas extremadas de reducirlo a fundamentalmente literato o fundamentalmente historiador. En vida y en obra ¿no fue Garcilaso hombre dado en varias direcciones? Por lo demás, el problema de su veracidad, harto complejo, dista mucho de resolverse.

Así tenemos a este soldado viejo perulero, que dejó la nobleza toledana y arraigó en Indias y a mucha honra. Al quedarse con el último galeote, le dijo:

estoy por daros veinte puñaladas y no lo hago por no ensuciar las manos en hombre tan vil y bajo como vos, que habiendo sido soldado en el Perú no os desdeñéis en remar en una galera ${ }^{49}$.

Y lo soltó, dándole de golpes. Esto lo escribe un mestizo peruano nacido hace justamente cuatrocientos cincuenta años. Las letras novohispanas y peruanas tuvieron pronto asunto y autores de alto valor. 